\title{
O INTEGRALISMO, AS NOVAS GERAÇÕES E O PROBLEMA DA CONSCIÊNCIA HISTÓRICA
}

\author{
Márcio Santos de Santana*
}

\begin{abstract}
Resumo: $O$ artigo pretende demonstrar que o integralismo considerava as novas gerações como o segmento estratégico para a promoção de mudanças na sociedade, garantindo a reprodução social do movimento, por meio da formação de novos líderes. As motivações para a precocidade na socialização ideológica dos membros estão relacionadas com a concepção autoritária do movimento integralista, interessada em evitar que as crianças e os jovens estruturassem uma consciência histórica própria. O discurso do movimento enfatiza a necessidade de salvaguarda dos valores, de reconstrução da civilização, de tomada de consciência por parte das novas gerações, mas, ao mesmo tempo nega qualquer possibilidade para que as crianças e os jovens tenham vivencias autônomas.
\end{abstract}

Palavras-chave: Integralismo. História Política. Educação Histórica. Utopia. Consciência Histórica.

\begin{abstract}
The article argues that the integralism thought the younger generation as the strategic segment for promoting change in society, ensuring the social reproduction of movement through the formation of new leaders. The motivations for the early socialization of ideological members are related to the authoritarian conception of the movement integralist, interested in preventing children and young people creat a historical consciousness itself. The discourse of the movement emphasizes the need to safeguard values, reconstruction of civilization, of awareness on the part of the new generations, but at the same time denies any chance for children and young people have autonomous livings.
\end{abstract}

Keywords: Integralism. Political History. Historical Education. Utopia. Historical Consciousness.

\footnotetext{
* Professor no Departamento de História da Universidade Estadual de Londrina (UEL).

E-mail:msantana@uel.br
} 
O período entreguerras teve, como uma de suas características marcantes, o acentuado antiliberalismo. Os governos europeus gradualmente foram ocupados por indivíduos e grupos políticos detentores de ideias contrárias aos princípios liberais, a saber: igualdade de todos perante a lei; soberania do povo; respeito ao princípio de governo representativo; liberdade de negócios e liberdade de expressão, publicação e reunião. O século XIX foi marcado pelo auge da "civilização liberal", cujas principais características foram a crença nos valores da razão, do progresso científico e tecnológico, da transformação dos indivíduos através da educação, do debate público, entre outros. Contudo, decorridos poucos anos do término da Primeira Guerra Mundial, os europeus presenciaram um retrocesso contínuo e incessante do liberalismo.

O processo de retração das ideias liberais do cenário político mundial rapidamente chegou ao Brasil. Movimentos políticos variados desdenhavam do liberalismo, considerado, nessa nova conjuntura, como incapaz de solucionar os problemas e dilemas da sociedade. O liberalismo perdera, definitivamente, o status de exclusividade como argamassa do tecido social e de fórmula perfeita de organização e gerenciamento da economia. Novas formas de organização da sociedade surgiram, alcançando elevado prestígio junto à sociedade. $\mathrm{O}$ nazi-fascismo conquistou espaço na opinião pública. Os adeptos e admiradores foram se multiplicando. No Brasil tal ideologia alcançou espaço relevante no debate político, sendo os integralistas seus principais entusiastas. Nesse complexo e intrincado processo a democracia foi soterrada. Aliás, democracia que não havia sido erigida de maneira consistente, pois é arbitrário categorizar a Primeira República brasileira como um período democrático.

As alterações ocorridas nas sociedades alcançaram os segmentos jovens, pelo simples motivo de que nenhum segmento permaneceu incólume a elas. A reformulação do papel do Estado não se restringiu ao âmbito econômico. Os donos do poder lançaram mão da engenharia social para implantar seus projetos de poder. A infância e a juventude eram os segmentos perfeitos para a concretização de tais ambições, uma vez que permitiam a moldagem dos futuros participantes da sociedade em padrões considerados corretos pelos reformadores sociais. Numa fase da História na qual o Ocidente buscava a reconstrução da Civilização, destruída pela Grande Guerra, as novas gerações se convertem rapidamente no símbolo de um novo paradigma de sociabilidade. ${ }^{1}$

AAção Integralista Brasileira (AIB) foi fundada por Plínio Salgado em 1932. As estimativas são de que o partido tivesse alcançado já em 1936 entre seiscentos mil e um milhão de adeptos. Tornou-se, então, o primeiro partido nacional a possuir uma organização de massa. Entre 1930, ano da revolução que conduziu Vargas ao poder, e 1937, quando da implantação do Estado Novo, 
a Ação Integralista manteve relações políticas intensas e contraditórias com o governo federal, ora recebendo apoio e sendo chamada a apoiar as ações do governo, ora sendo rechaçada e mesmo perseguida. ${ }^{2}$

A instauração do Estado Novo alterou o quadro. Um mês após a promulgação do novo regime o governo decretou o fechamento de todos os partidos políticos, inclusive da AIB que havia participado da articulação política que levou ao golpe de 1937. Tal medida foi um duro golpe nos planos políticos da organização que almejava participar das próximas eleições presidenciais com a candidatura de Plínio Salgado, sua liderança máxima. Sem alternativas, o partido foi registrado como Associação Brasileira de Cultura em janeiro de 1938 , acatando parcialmente as premissas do novo regime. ${ }^{3}$ Em reação às medidas governamentais, os integralistas optaram pelo uso das armas para chegar ao poder. Sendo assim, decidindo por uma solução de força como tentativa de depor o presidente Getúlio Vargas, em março de 1938, numa primeira tentativa, o alvo foi uma rádio no Rio de Janeiro. Posteriormente, ocorreu a segunda tentativa golpista, dessa vez em maio. O episódio ficou consagrado na historiografia como "Putsch" ou "Intentona Integralista" e findou em fracasso, seguido da ação repressora do Estado, embora tenha apresentado sólidas chances de vitória. ${ }^{4}$

Os Integralistas foram tratados pelo governo Vargas de maneira contraditória, conforme observamos anteriormente. Contudo, examinando documentação produzida pelo DEOPS ${ }^{5}$, podemos concluir que os membros do sigma não encontraram grandes empecilhos à sua ação, ao menos nos anos iniciais. A documentação policial registra essa ambiguidade, resultado das tensões e impasses originados nas alianças políticas. Em decorrência de nosso tema de estudo, concentramo-nos no exame de episódios envolvendo a juventude. Tal análise, entretanto, foi dificultada devido a não localização de prontuários específicos sobre a juventude integralista. Assim, fomos instados a localizar documentos referentes ao tema nos volumes que compõem o prontuário da AIB e em prontuários de dirigentes. No fundo DEOPS não foi possível localizar o prontuário de Irene de Freitas Henriques ou da Secretaria Nacional de Arregimentação Feminina e dos Plinianos da qual foi titular.

Um episódio ocorrido em 17 de maio de 1935 revela a alteração de tratamento por parte da Polícia com relação aos integralistas, na conjuntura posterior à Lei de Segurança Nacional (04/04/1935), embora destaque a relativa liberdade de ação, quando em comparação com a situação política da esquerda, alvo primordial da repressão. Esse episódio é revelador da ênfase da Polícia Política no combate às aglomerações humanas. Os jovens foram presos por andarem em grupo, realizando uma passeata, o que preocupava as autoridades, sobretudo após a promulgação da Lei de Segurança Nacional que tornou mais 
rígida a legislação sobre controle social. A agitação no meio estudantil foi intensa naqueles anos, com representantes em todos os espectros políticos. ${ }^{6}$

O jornal Diário de São Paulo ${ }^{7}$ dá conta da prisão de vários integralistas. Nesse dia um grupo de estudantes foi detido quando passava pela Rua Direita, em direção à Rua 15 de Novembro. Os integrantes foram interceptados e levados à polícia Central, sendo posteriormente encaminhados à Delegacia de Ordem Política, onde ficaram por algum tempo. A matéria dá conta de que vários menores teriam sido detidos, sendo a grande maioria estudantes. Entre os envolvidos estavam Roland Cavalcanti de Albuquerque Corbisier, Lafayette Soares de Paula, Carlos Jacyntho de Barros, Joaquim Magalhães Costa e Bento Luiz de Almeida Prado, notadamente membros de famílias socialmente bem situadas. A reação dos jovens presos se deu rapidamente e, em 29 de agosto de 1935, alguns estudantes integralistas entregaram ao juiz da primeira Vara Criminal da cidade uma queixa-crime contra Eusébio Egas Botelho, Superintendente da Ordem Política e Social, devido à prisão que haviam sofrido. Enfatize-se que os integralistas desfrutaram o direito de contestar uma ação estatal, inclusive acenando com a possibilidade de processar uma autoridade policial, fato impensável para qualquer militante da esquerda.

O exame dos prontuários dos indivíduos anteriormente citados revela o menor "grau de periculosidade" que a Polícia Política atribuía aos partidários do integralismo em comparação com o comunismo. No prontuário de Bento Luiz consta apenas o registro de uma detenção sofrida por ele em 1941, ocasião na qual já havia alcançado a maioridade. Sobre a passeata da rua Direita não há qualquer menção. Como prova de seu vínculo com a AIB consta uma carteira de filiado anexa aos autos. Nos prontuários de Carlos Jacyntho, aluno da Faculdade de Direito, e Joaquim de Magalhães, aluno da Escola Politécnica, consta apenas uma lista com os nomes das pessoas detidas na passeata da Rua Direita. ${ }^{8}$ No prontuário de Lafayette Soares, também estudante da Faculdade de Direito, consta um relatório de investigações dando conta de que o mesmo estivera foragido por algum tempo, tendo sido localizado em 2 de julho de 1938. Em anexo há uma cópia da lista das pessoas envolvidas na passeata da Rua Direita. ${ }^{9}$

Dentre os envolvidos citados, apenas Roland Corbisier foi interrogado pela Polícia Política, mas isso se deu em decorrência da tentativa de golpe por parte dos integralistas. O suspeito compareceu em 26 de março de 1938 para prestar esclarecimentos. Disse na ocasião ser membro da AIB desde a sua fundação e que, em 1935, foi Chefe do Departamento Universitário do partido. Questionado sobre possível participação no levante armado, Corbisier negou veementemente qualquer participação ou conhecimento do evento. ${ }^{10}$

A juventude das lideranças e dos seus militantes é uma das características mais relevantes do Integralismo. Em 1933 a maioria dos integrantes tinha 
menos de 25 anos. Dado elucidativo diz respeito à composição etária das lideranças: 3/4 delas, de caráter regional ou nacional, estavam abaixo dos 30 anos. Exemplo significativo dessa concentração etária reside no fato de que o Departamento de Doutrina, área vital para qualquer agrupamento político, estava sob a direção de Miguel Reale, então com apenas 25 anos de idade. O aspecto geracional é de suma importância, na medida em que, via de regra, movimentos de massa prometem grandes melhorias nos rumos da sociedade, uma profunda alteração na trajetória evolutiva do país no qual está instalado. ${ }^{11}$

Combinando instrumentais analíticos oriundos da História Política e da Educação Histórica, o artigo pretende demonstrar que o integralismo considerava as novas gerações como o segmento estratégico para a promoção de mudanças na sociedade. Uma vez que necessitaria formar novas lideranças, os jovens garantiriam a reprodução social do movimento. Em outras palavras, um agrupamento político que clamava por um país novo buscaria pessoas daquela faixa etária, pois elas ainda não teriam concluído o processo de socialização, tornando não apenas mais fácil a tarefa de cooptação, mas também garantindo a produção de futuras lideranças.

Analisando as origens do Integralismo podemos subsidiar nossa hipótese com alguns dados mais detalhados. Em 24 de fevereiro de 1932, na sede do jornal $A$ Razão em São Paulo, foi realizada a primeira reunião visando à formação da Sociedade de Estudos Políticos (SEP), que produziria estudos sobre os problemas e potencialidades do Brasil. A assembleia de fundação ocorreu em 12 de março. Plínio Salgado presidiu ambas as reuniões. Importa aqui constatar a composição inicial dessa sociedade: jovens intelectuais paulistas e estudantes da Faculdade de Direito do Largo São Francisco. Assim sendo, podemos afirmar que a juventude das lideranças é um traço que acompanha o movimento desde as suas origens. ${ }^{12}$

Quando o manifesto de outubro de 1932 foi publicado em São Paulo, oficializando a fundação da Ação Integralista, um grupo de estudantes da Faculdade de Direito de Recife lançou outro documento apoiando a iniciativa paulista. O manifesto de Recife sustentava que

a mocidade nordestina de modo algum poderia ficar indiferente. E muito menos alunos da Faculdade de Direito do Recife. Esta escola, que certa vez ouviu proclamar a morte da metafísica, precisa tornar-se uma célula vivíssima desse grande movimento de renovação política, social e espiritual. ${ }^{13}$

O manifesto de Recife utiliza o vocábulo mocidade com sentido semelhante ao termo juventude. A essência missionária dos manifestos de 1932 
deve ser destacada, uma vez que os estudantes daquela faculdade não ficariam indiferentes aos problemas e tensões políticas de sua época, demonstrando, dessa maneira, a precoce penetração do Integralismo nos meios universitários. Mesmo se tratando de um manifesto de adesão, onde só se poderia esperar o tom laudatório e revelador da tomada de posição, a autoimagem forjada por aquele grupo impressiona, pois tomou para si o fardo de concretizar a renovação prometida. Era uma tarefa para a nova geração que a recebia com todo vigor, segundo o discurso disseminado. ${ }^{14}$

As motivações para a precocidade na socialização ideológica dos membros estão relacionadas com a concepção autoritária do movimento integralista, interessada em evitar que as crianças e os jovens estruturassem uma consciência histórica própria. ${ }^{15} \mathrm{~A}$ ortodoxia seria preservada por meio de tal expediente. Liberdade de consciência, autonomia, individualidade eram valores com o quais o movimento não concordava. Tais valores eram tidos como responsáveis pela degradação das tradições e derrocada da civilização. Sendo assim, uma vez conquistada à adesão dos pais, a organização esperava que os filhos seguissem os mesmos passos. Por conta disso, a recomendação era de que os descendentes de integralistas fossem batizados quando ainda bebês, conforme os rituais oficiais do movimento, cujas indicações estavam registradas nos protocolos da AIB, de tal modo que a tradição fosse perpetuada. Essa manobra era implementada através da disseminação de ideias sobre a juventude por meio da propaganda doutrinária divulgada pelos jornais ou outros meios. ${ }^{16}$ De um modo geral,

As narrativas sobre os plinianos mostram-nos, na grande
maioria das vezes, como intrépidos soldadinhos, superando
todo tipo de dificuldades, e enfrentando até o chamado
perigo comunista. Eram vistos como selvagens, inclinados,
como num impulso natural, à vida do campo, e identificados,
nesse esquema ideológico, como os verdadeiros brasileiros.
Verdadeiros, de acordo com a oposição que Salgado faz entre
espiritualismo e materialismo, porque ligados ao interior
do país, em oposição à cidade cosmopolita, tida como o
antro dos males vindos de fora. Segundo a propaganda do
Sigma, eles eram retratados como disciplinados a ponto de
sacrificarem não somente alguns prazeres da infância em
prol do movimento camisa-verde, mas também a vida, na
defesa dos valores integralistas. ${ }^{17}$

Esse zelo para com a tradição transparece no texto de um panfleto intitulado Mocidade de Cachoeira! Pais de Família ${ }^{18}$, documento revelador da retórica utilizada para convencimento de seu público alvo. O princípio da 
autoridade e da hierarquia é afirmado logo no primeiro parágrafo ao definir o integralismo como um pai "com seus braços abertos para receber em seu seio a paz da família, de seu Deus e de sua dignidade". Além de consolidar o princípio do pai como chefe da família, verdadeiro guia de sua esposa e filhos, reafirma a necessidade da presença divina e, por extensão, da dignidade ausente fora do universo integralista. Note-se que o texto é direcionado às famílias e não aos indivíduos, sendo coerente com a premissa corporativista de sua ideologia. ${ }^{19}$

$\mathrm{O}$ adversário a ser derrotado é o comunismo. Seus adeptos, afirmava o texto, embora se proclamassem como os mensageiros da liberdade e da igualdade só conduziriam as famílias para a bancarrota. A missão integralista era empreender uma "cruzada sacrossanta" dos "homens de dignidade" contra os "vermes que têm corroído os corações de certas famílias corrompidas". A construção textual é forte e certeira, gerando uma imagem negativa para o adversário, no caso os comunistas, caracterizados como verdadeiros vermes que atacavam diretamente o coração, ou seja, o centro vital do ser humano. $\mathrm{O}$ comunismo, na sequência, é associado à lepra, doença de altíssima gravidade, sobretudo naquela época.

Para fundamentar a suposta obscuridade de seus adversários o panfleto apresenta alguns dados:

Na Rússia também queriam-nas [a liberdade e a igualdade], mas estas saíram-lhes ao contrário dos desejos ambiciosos. Escravidão e desigualdade. Enquanto seus governos nadam em ouro e em banquetes regados a champagne, um trabalhador tem para seu sustento 200 gramas de pão feito de milho e batatas; 100 gramas de toucinho e $1 / 2$ garrafa de aguardente.

Contudo, como nem todas as famílias estavam sob a influência comunista, fato considerado positivo pelos partidários do Sigma, a mensagem do panfleto é encerrada com um convite ao comparecimento das famílias da cidade de Cachoeira na sede integralista da cidade. ${ }^{20}$

A preocupação com as novas gerações é um dos pilares da reflexão intelectual de Plínio Salgado precedente à fundação da Ação Integralista Brasileira, cuja obra é marcada por um constante temor sobre uma possível dissolução da Civilização. Seu mote primordial é empreender uma análise da sociedade, assim como erigir um projeto de nação para o Brasil, entendida como uma arquitetura imperfeita. $\mathrm{O}$ pensamento foi erigido sobre a oposição materialismo comunista versus espiritualismo integralista. ${ }^{21}$

O chefe integralista fazia uma leitura do mundo sob a ótica de crise civilizacional. Tal crise teria como ponto central o cenário de confusão e 
desnorteamento com relação às ideias que deveriam presidir a vida social. Assim, o momento histórico era de decisão, de tomada de posições, pois estava em jogo a nacionalidade brasileira, precariamente constituída. Desta forma, acreditava Plínio, ou se constituiria essa nacionalidade "dentro das nossas condicionalidades históricas, geográficas e sociais" ou o resultado dessa omissão poderia ser a "abdicação completa de nossos direitos de afirmação, de nossa fisionomia de povo e de país". ${ }^{22}$

$\mathrm{O}$ integralismo, na crença de seu fundador, possuía as respostas para retirar o país dessa trajetória de crise. O doutrinador, nesse sentido, compreendia que qualquer transformação social seria possível somente após uma intensa alteração no plano das ideias que orientariam a ação. Cumprido tal imperativo, escreve em A psicologia da revolução (1933), "o homem pode interferir na marcha social. E quando a sociedade está se dissolvendo, e quando vai o País a pique de se desagregar, então essa interferência... se impõe como um dever". ${ }^{23}$

A cosmovisão de Plínio revela o seu posicionamento perante a modernidade. $\mathrm{O}$ primeiro impasse considerado pelo autor é relativo à tensão entre a dimensão individual e a coletiva de existência, problema fulcral para aquela primeira metade do século XX, sobretudo em razão da escalada nazifascista na Europa Ocidental. Em sua concepção, a humanidade seguiria uma trajetória orientada por dois planos distintos, sendo "o primeiro coletivo, global, movimento de massas, rumos inconscientes de povos", enquanto o segundo seria "individual, singular, atitude isolada do homem, desferindo impulsos modificadores". Nesse choque de contrários, supostamente aceito pelo Integralismo, conforme ressalta seu líder, processa-se a história, cujo curso e sentido poderiam ser alterados por ação revolucionária, desde que com franca motivação espiritualista, realizada após uma correta interpretação da oportunidade histórica e do sentido social dessa ação. ${ }^{24}$

Esse impulso renovador que Plínio Salgado nutria acompanha seu pensamento desde muito antes. Em Literatura e Política, obra da segunda metade da década de 1920, o tema já estava presente. Num artigo sugestivamente intitulado Diretrizes da Nova Geração sustenta, bem ao seu estilo, que a geração que se formava não apenas tinha uma missão a cumprir, como seria a portadora de profundas transformações. Previa o desabrochar de uma genuína "revolução literária". Essa nova conjuntura teria o mundo artístico-literário subordinado aos interesses da política. Nesse sentido, seria, portanto, o resultado da

fusão da arte, da finalidade social, com a política, norteada por um sentimento de harmonia dos movimentos relacionados da vida nacional, e uma e outra, fundada em nossa antropogeografia, fundidas na aspiração da 
coletividade - há de provir, como todas as grandes coisas, de uma coisa bem simples: da revolução literária. ${ }^{25}$

Os valores do Integralismo foram disseminados para o seu público-alvo, haja vista que, para o movimento,

tão importante quanto a ideologia defendida era o apelo à permanente mobilização, por meio de desfiles minuciosamente coreografados, comícios disciplinados, símbolos, palavras de ordem, bandeiras, canções, discursos dramatizados, estandartes, uniformes, insígnias e rituais, que configuravam uma mística, um apelo messiânico que incitava à ação violenta. ${ }^{26}$

Esse apelo messiânico para a recriação do mundo era precedido de um diagnóstico extremamente pessimista quanto ao momento vivido pelo país. A vida nacional encontrar-se-ia em "hora trágica" em que sobressaltava "o acre cheiro de pólvora e de lama", ou seja, dos estragos oriundos da Primeira Guerra Mundial. A preocupação em reproduzir a doutrina para gerações futuras é explícita, assim como a legitimação dos atos do movimento. A Revista Panorama, um dos mais importantes periódicos ${ }^{27}$ do Integralismo sustenta, em seu texto de apresentação, ter escapado dessas amarras culturais e por isso vinha a público para divulgar o pensamento Integralista, único capaz de apresentar soluções. Assim sendo, o Integralismo seria o defensor de uma revolução que forjaria uma nova ordem. Esta seria realizada "no plano da inteligência, pela objetivação segura de uma finalidade inspirada em conceitos doutrinários e consoantes as realidades sociais e econômicas dia a dia pesquisadas no cenário nacional". ${ }^{28}$

A ordem era o pressuposto básico para a proliferação dos ideais do movimento, bem como de seu possível crescimento. Assim, a revista Panorama pretendia ser "um laboratório de ideias e ao mesmo tempo uma escola de futuros estadistas da Nação Integral". Era preciso transmitir à juventude uma trajetória: "o estudo consciente, honesto, sincero, dos problemas mundiais e nacionais, segundo um Pensamento, através de um Método, objetivando uma finalidade ampla, luminosa e digna". ${ }^{29}$ Agir pedagogicamente era o ato de inserir o outro em uma doutrina fechada através de um método. A questão crucial é que esse processo não comportava críticas, apenas obediência e execução. Em outras palavras era o império do consenso.

O projeto integralista demandava o apoio da instituição escolar e dos professores, sobretudo dos católicos, considerados aliados naturais da causa. Maria Letícia Ferreira Lima, em artigo publicado no mesmo periódico, clama 
pela participação dos professores católicos na implantação de um nacionalismo capaz de construir "uma pátria livre e forte". A autora traça um diagnóstico negativo da situação na qual se encontrava o Brasil naquele momento: os jovens eram ora indiferentes à religião ora hostis à mesma. A função dos educadores católicos era combater aquele "ambiente desagregador" onde imperava a conspiração "contra a integridade da nação, contra a sua fé, a sua cultura, a sua vida enfim". ${ }^{30}$

O papel da escola primária, bem como o de toda a instituição escolar, é de via dupla, pois pode fornecer "uma grande linha de uma doutrina segura", mas também pode guiar os educandos "pelos meandros tortuosos de uma filosofia desagregadora e má". ${ }^{31}$ Naquele momento, a juventude brasileira estaria vivendo um momento de "fraqueza cívica", o que a levaria a uma "dissociação da vida nacional", mantendo-se em "atitude de impassibilidade e dormência" diante das demandas e problemas da época. Essa situação precisava ser rompida e a juventude conduzida a um ambiente dinamizado pelo patriotismo. O papel do professor diante desse esquema era o de implantar desde cedo no aluno "notas de variedade e reflexão ante a realidade da pátria". ${ }^{32}$ Portanto, nessa configuração, a escola é compreendida como um centro irradiador do patriotismo, força capaz de combater a mesmice e a pasmaceira em que se encontraria aquela juventude.

As relações paradoxais entre o governo Vargas e o Integralismo são evidenciadas por um artigo escrito por Isaias Alves, membro do Conselho Nacional de Educação, discutindo A Disciplina na Escola Alemã. ${ }^{33}$ A autoridade do professor em sala de aula volta a ser tematizada, por meio da comparação das realidades existentes na Alemanha, na fase da República de Weimar e posteriormente à ascensão do nazismo. $\mathrm{O}$ governo nazista reestruturou a escola, através de um ato promulgado em 31 de janeiro de 1933, restituindo ao professor o prestígio que possuía durante a República de Weimar. A Alemanha, defende Alves, tardara com tal medida, posto que o governo soviético houvesse realizado mudanças do gênero em 1932. As alterações ocorridas nos dois países mostrariam a compreensão que os europeus possuíam quanto às necessidades específicas dos jovens em seu preparo para a vida. A psicologia deveria ser a guia desse processo em razão de seu potencial para interpretar e explicar "perfeitamente o contraste das tendências cuja luta perturba a personalidade do aluno". A "grande maioria" destes somente alcançaria o "devido equilíbrio" por meio da orientação intensa de um mestre dotado de sólida autoridade.

Identifica-se no discurso do autor a ressonância do culto à figura do Chefe e o combate ao individualismo típicos do ideário integralista. $\mathrm{Na}$ escola alemã a autoridade do professor sobre seu aluno teria sido retomada, pois o novo regime que lá havia se instaurado desejava conseguir uma "educação das crianças na obediência e no respeito a seus maiores”. No período em questão, 
o Nazismo foi tido como modelo em muitas outras nações e seus horrores viriam a público somente algum tempo depois.

A doutrina integralista abarcava uma concepção do homem e da sociedade fundamentada num humanismo espiritualista e num ideal harmônico de organização social, cuja inspiração era o ideal medieval de sociedade coesa e estamental. ${ }^{34}$ Isaias Alves acredita que, no Brasil, não seria necessário empregar tanta ênfase como na Alemanha. Seria importante, argumenta, que a juventude fosse conduzida a uma concepção altruísta de mundo, levando os jovens a escolher suas profissões baseando-se nas especificidades de cada ser humano, de modo que cada um pudesse se capacitar para exercer um papel dentro do "maquinismo da sociedade". Cada integrante da coletividade deveria viver a sua vida, sempre tendo uma especial preocupação com os interesses coletivos e a eles se dedicando.

O padre Hélder Câmara posiciona a pedagogia integralista perante outras propostas existentes. ${ }^{35} \mathrm{O}$ liberalismo, o socialismo, o capitalismo internacional e o judaísmo eram as grandes ideologias consideradas pelo integralismo como os adversários do movimento. Câmara indaga sobre como fazer com que as crianças pobres comparecessem às escolas.

O liberalismo foi criticado em razão do suposto tratamento ofertado aos pobres e o método de inclusão das crianças na vida escolar. Segundo o autor, o Estado liberal tomava medidas paliativas e assistencialistas, fornecendo bolsas de estudos e outros expedientes similares, sem atacar o problema em suas raízes. No entendimento de Câmara, porém, tal postura seria ofensiva, na medida em que se assemelhava ao ato de dar esmolas, tido como "meio anormal de conquistar a vida". Nesse sentido, por não ser a necessidade do pobre, "dá-la a um homem capaz é humilhá-lo necessariamente, é revoltá-lo". ${ }^{36}$

Os partidários da Escola Nova-reputados "pseudo-renovadores" no artigo - são apontados como adversários, por serem promotores de um ataque contra a tradição e o espiritualismo do integralismo. As palavras de Câmara se tornam mais ríspidas ao sentenciar o caráter ilusório trilhado por aquele grupo de pedagogos:

Quanta ilusão entre educadores sinceros e devotados! Dirse-ia que eles se alheiam da vida real. Temendo, talvez, invasões da política no terreno sagrado da educação, não percebem que debalde se tentará a modificação de uma ordem estabelecida pela simples mudança da escola, uma das forças, uma só, do meio social trabalhando por influências bem maiores. ${ }^{37}$ 
Se os educadores da Escola Nova eram bem intencionados nos seus propósitos, encontravam-se, porém, equivocados quanto à maneira de realizálos, defende. Seriam necessários investimentos que melhorassem a qualidade de vida do proletário com um todo. Por isso, questiona: de que valeria a educação física se o filho do trabalhador estivesse subnutrido ou, ainda, de que valeria a educação intelectual para um operário tratado como "uma máquina sem direito de ser homem"? ?3

As educações estéticas e sociais não teriam sentido na vida do trabalhador, uma vez que esta não tinha beleza e nem harmonia onde exercitar os princípios aprendidos em sala de aula. Finalmente, num cenário como esse, a educação religiosa corria o risco de fazer o papel de ópio do povo. O modelo pedagógico russo, na visão de Câmara, possuía um aspecto exemplar que era a objetividade, mesmo que para finalidade "diabólica". Mesmo considerando negativa a decisão soviética de subordinar todas as dimensões da vida à economia, destaca a firmeza daquela nação em superar o "meio termo" dos liberais.

Conclui Hélder Câmara que se liberais e socialistas não foram capazes de apresentar medidas concretas para a melhoria das condições de vida da população, ao passo que os integralistas seriam possuidores das virtudes necessárias para tal. Assim sendo, apenas os educadores partidários do Sigma eram "coerentes e justos", uma vez que haviam superado "as vacilações criminosas dos mestres burgueses" e, por conta desse feito, construído uma alternativa original e viável para a época. Essa alternativa tinha ainda o mérito de não conduzir a educação para os "excessos dos mestres russos". Destarte, os educadores integralistas não se tornariam "socialistas intelectuais" e nem "burgueses práticos" em virtude de "conservantismo e timidez". 39

Uma vez demonstrada a importância das novas gerações e seu papel social no âmbito da AIB, compete refletir, ainda que brevemente, sobre o lugar desse segmento etário-cultural na simbologia do movimento. O integralismo estava dividido em diversos departamentos, cada um deles encarregado de uma área específica, porém estando todos os seus titulares subordinados a Plínio Salgado. Com o decorrer do tempo, a estrutura administrativa dos integralistas alcançou um nível de burocratização que provocou o isolamento do Chefe Nacional de suas bases. Assim sendo, Plínio Salgado passou a ter contato com a coletividade integralista através dos discursos, artigos e livros. Os estatutos de 1934, elaborados durante o Congresso de Vitória, previam que o Chefe Nacional se comunicaria com os integralistas através dos Departamentos Nacionais, esses com os Chefes Provinciais e assim sucessivamente, numa postura descendente de poder. Os estatutos de 1936 têm maior relevância para o tema ora em discussão. Elaborado durante o Congresso de Petrópolis, esse documento traz o registro de importantes alterações organizacionais. Nessa ocasião, foi 
criada a Secretaria Nacional de Arregimentação Feminina e dos Plinianos (juventude), entregue ao comando de Irene de Freitas Henriques, que comandou a pasta até o fechamento da AIB em 1938. Os antigos departamentos foram transformados em secretarias, mas continuavam diretamente subordinados ao Chefe Nacional. ${ }^{40}$

Os Plinianos receberam uma estrutura organizacional testada anteriormente no Departamento da Milícia, transformado em Secretaria de Educação em 1936. Foram encarregados das atividades paramilitares, esportivas, cívicas e de mobilização eleitoral. O regulamento da secretaria previa que lhes caberia "reunir, disciplinar e educar, através da escola ativa, todos os brasileiros, de ambos os sexos, até 15 anos de idade, de modo a realizar o seu aperfeiçoamento moral, cívico, intelectual e físico" ${ }^{41}$ A reestruturação, além de novas atribuições, promoveu também uma alteração no vocabulário, abandonando a linguagem explicitamente militar que vigorava na antiga milícia: decúria, terço, bandeira e legião ${ }^{42}$ Portanto, essa organização faria a socialização ideológica das crianças e jovens que aderissem ao movimento. Os grupos existentes entre os Plinianos seguiam um ordenamento etário: Infantes (de 4 a 6 anos), Currupiras (de 6 a 9 anos), Vanguardeiros (dos 10 aos 12 anos) e Pioneiros (dos 13 aos 15 anos).

A socialização ideológica é um tópico de extrema importância para qualquer movimento político. No caso integralista veremos que foi um aspecto muito valorizado. Um primeiro mecanismo a ser ressaltado diz respeito aos rituais. Os integralistas criaram um rito específico para os batismos, cujas cerimônias continuaram a ser realizadas em templos e igrejas cristãs, mas contando com a colaboração do Chefe local e com a presença da comunidade integralista.

O protocolo obedecia a um ritual. Todos os participantes do batismo, ou seja, pais, padrinhos e demais convidados deveriam ir para o templo trajados com a camisa-verde. Os Plinianos tinham um papel nessa ocasião: ficavam próximos à pia batismal e, juntamente com os demais integralistas, deveriam erguer o braço no exato instante em que a criança fosse abençoada pelo sacerdote. Terminado o batismo, a criança deveria ser enrolada com a bandeira integralista e, ainda dentro da Igreja, era apresentada aos presentes conforme o seguinte roteiro:

Companheiros! (nome da criança), recebeu o primeiro sacramento da fé cristã. Ao futuro pliniano, o primeiro anauê. Os presentes responderão Anauê. Ao final dessa cerimônia, os plinianos formarão uma ala, de braços erguidos, por onde sairão todos os integralistas do templo. ${ }^{43}$ 
A participação dos plinianos não era restrita apenas aos batismos. Em cerimônias solenes de casamentos havia também um protocolo a ser seguido. Primeiramente, os integralistas ocupavam a igreja, ficando as mulheres (BlusasVerdes) à direita e os homens (Camisas-Verdes) à esquerda de quem entra. Os Plinianos e Plinianas deveriam ser posicionados em local "conveniente", ficando a critério dos organizadores determinar o lugar exato. Poderiam portar galhardetes com as cores do país e do integralismo. Familiares e autoridades de maior graduação, além de convidados não-integralistas ficariam na capela-mor. A autoridade de maior graduação presente ao evento deveria, de braço erguido, saudar o casal com as seguintes palavras: "o Chefe Nacional considera-se presente a esta cerimônia e deseja todas as felicidades ao novo casal." 44

A AIB possuía ainda outra forma de socialização ideológica: hinos e marchas para serem apresentados em eventos integralistas. A marcha da juventude é objeto de maior importância para análise.

O Brasil acordou para a glória

Nós já somos a Pátria que vem

Eia! Avante para a História

Os Plinianos já marcham também.

Para a frente marchemos

Vai conosco um Brasil grande e forte

pela Pátria morreremos

nossos bravos não temem a morte. ${ }^{45}$

A marcha expressa nítida mensagem. O Brasil era um país adormecido, inerte, mas que havia acordado e dinamicamente seguiria sua trajetória natural na história. Alcançar a glória era uma missão de todos, sendo função dos Plinianos trabalhar para a consecução desses objetivos. A índole militarista sobressai-se na ênfase dada à marcha, além da invocação à falta de limites: morrer pela Pátria, uma vez que verdadeiros guerreiros não temem a dimensão do sacrifício.

O Hino Integralista apresenta uma retórica especialmente direcionada à juventude, a quem é atribuída a missão de transformação do país. A mensagem não difere muito daquela transmitida pela Marcha da Juventude, contudo o chamamento à integração e participação é elemento mais presente. À nova geração caberia a realização das transformações almejadas pela AIB e seu Chefe Nacional, autor do hino. Vejamos:

Avante! Avante!

Pelo Brasil toca a marchar

Avante! Avante! 


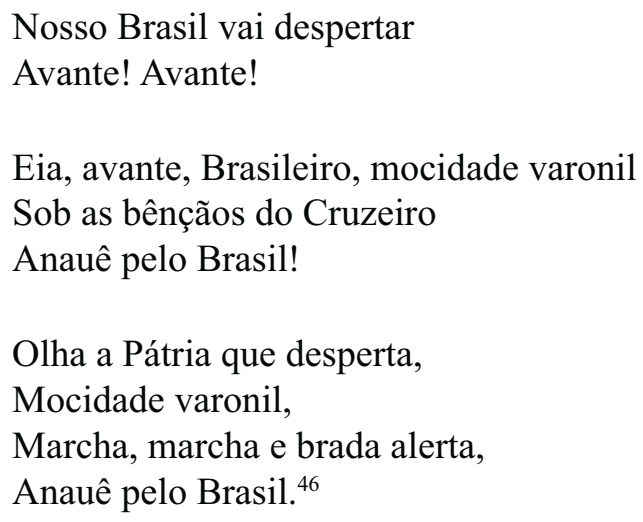

Os juramentos de fidelidade para ingresso e promoção constituem um terceiro mecanismo de socialização. Os infantes eram admitidos após a realização de ritual semelhante ao dos escoteiros. Nessa ocasião, o indivíduo prestaria um juramento, no qual pronunciaria os seguintes dizeres:

Prometo ser um soldadinho de Deus, da Pátria e da Família; prometo ser obediente a meus pais, a meus mestres e a meus chefes; prometo ser amigo de meus irmãos, colegas e companheiros, prestando-lhes serviços, defendendo-os e amando-os; prometo ser aplicado nos estudos para tornarme útil a Deus, à Pátria e à Família; prometo cumprir o Regulamento dos Plinianos. ${ }^{47}$

Os vanguardeiros e os pioneiros, além dos Camisas-verdes, prestavam o juramento à bandeira em grandes solenidades. Na ocasião, o participante deveria proferir as seguintes palavras:

Bandeira da minha Pátria: Prometo servir ao Brasil na hora da alegria e na hora do sofrimento, no dia da glória e no dia do sacrifício. Prometo respeitar a liberdade, a justiça e a lei. Prometo defender na sua pureza o legado moral e na sua integridade, o patrimônio territorial que recebi dos meus antepassados. Salve a Bandeira do Brasil. ${ }^{48}$

Há entre os dois juramentos uma gradação de caráter pedagógico. $\mathrm{O}$ primeiro juramento leva em consideração apenas a dimensão mais imediata da vida da criança, ou seja, preocupa-se em posicionar o indivíduo perante a coletividade e seus valores, ao passo que o segundo juramento introduz abstrações e valores mais complexos, ao invocar o patriotismo e sacrifício individual em benefício do Integralismo. 
Em suma, o Integralismo teve ampla atuação sobre o público jovem. Variados campos políticos disputaram a influencia sobre as novas gerações. Malgrado as abissais diferenças de objetivos entre os seus projetos, havia um elo comum: o olhar instrumental lançado sobre as crianças e jovens. ${ }^{49} \mathrm{~A}$ formação do Homem Novo, utopia mais ampla que ultrapassou os estreitos limites desta pesquisa, passava obrigatoriamente pela infância e juventude..$^{50}$ A época contemporânea, conforme constatou um estudioso, foi dominada pelo mito da infância, no qual a criança é retratada como um período da vida marcado pela espontaneidade e pela naturalidade, qualidades supostamente perdidas na vida adulta, sendo, portanto, "um dos modelos daquele homem novo, mais livre e mais genuíno, não-repressivo e não autoritário", cujo projeto "visa a educação nas sociedades atuais, democráticas e libertárias". ${ }^{51}$ Essa projeção não tardou a ser estendida às fases etário-culturais posteriores. A abertura para o futuro, elemento constitutivo da contemporaneidade, desembocou na ação governamental e de grupos políticos com o intuito especifico de construir o que entendiam por um futuro melhor para as novas gerações.

O caminho adotado negava qualquer possibilidade de autonomia, inviabilizando, de tal maneira, a formação de uma consciência histórica, entendida como um "trabalho intelectual realizado pelo homem para tornar suas intenções de agir conforme a experiência do tempo". ${ }^{52}$ Trata-se de uma forma da consciência humana e se estrutura a partir da vida prática. É inconcebível, portanto, a égide de uma consciência histórica sem a experiência do tempo vivenciada pela pessoa de forma autônoma. Aqui reside o ponto central do problema. O discurso do movimento enfatiza a necessidade de salvaguarda dos valores, de reconstrução da civilização, de tomada de consciência por parte das novas gerações, mas, ao mesmo tempo nega qualquer possibilidade para que as crianças e os jovens tenham vivencias autônomas.

O Integralismo, que ao contrário do comunismo, seu adversário principal, gozou de relativo apoio governamental e, por isso, espaço de atuação perante a opinião pública, também considerava um trabalho essencial o cuidado com a formação das novas gerações. A leitura que seu líder fazia da realidade histórica vivida naquele momento é muito reveladora, pois em sua percepção, a civilização corria sérios riscos de dissolução, sobretudo em razão do desenraizamento do homem moderno, cuja conexão com as tradições fora perdida. Sem esse esteio, restara ao Homem apenas um imenso vazio espiritual e a solidão do individualismo moderno de linhagem liberal. Nesse sentido, o caminho para a atribuição de um novo significado para o mundo moderno estaria no resgate da tríade Deus, Pátria e Família, assim como a reestruturação da civilização em novas bases. A missão das novas gerações era a de reconstrução do mundo em bases que usariam os valores da tradição 
para fornecer estabilidade à modernidade desenfreada que os integralistas vivenciavam e renegavam por temor aos seus resultados. Decorre desse temor a negação de autonomia da consciência para as novas gerações.

\section{NOTAS}

1 SEVCENKO, Nicolau. Orfeu extático na metrópole: São Paulo, sociedade e cultura nos frementes anos 20. São Paulo: Companhia das Letras, 1992.

2 SCHWARTZMAN, Simon; BOMENY, Helena Maria Bousquet; COSTA, Vanda Maria Ribeiro. Tempos de Capanema. São Paulo: Paz e Terra: Fundação Getúlio Vargas, 2000. p. 151.

${ }^{3}$ MAIO, Marcos Chor; CYTRYNOWICZ, Roney. Ação Integralista Brasileira: um movimento fascista no Brasil (1932-1938). In: FERREIRA, Jorge; DELGADO, Lucília de Almeida. $O$ tempo do nacional-estatismo: do início da década de 1930 ao apogeu do Estado Novo. 2. ed. Rio de Janeiro: Civilização Brasileira, 2007. p. 48. (O Brasil republicano, v. 2).

${ }^{4}$ MAIO, Marcos Chor; CYTRYNOWICZ, Roney. Op. cit. Para uma abordagem factual: SILVA, Helio. 1938: terrorismo em Campo Verde. O Ciclo Vargas. Rio de Janeiro: Civilização Brasileira, 1964. v. X.

${ }^{5}$ As fontes policiais analisadas neste estudo estão depositadas no Fundo DEOPS, Série Prontuários, sob a guarda do Arquivo Público do Estado de SP (AESP). O fundo é composto ainda por outras três séries: Delegacia Especializada de Ordem Social, Delegacia Especializada de Ordem Política e Arquivo Geral. No início da década de 1990, os acervos dos Estados de São Paulo, Paraná, Rio Grande do Sul, Rio Grande do Norte e Pernambuco foram entregues aos respectivos arquivos estaduais. PEDREIRA, Waldecy C. Reconhecimento do acervo das polícias políticas do Rio de Janeiro. In: DOPS - a lógica da desconfiança. Rio de Janeiro: Secretaria de Estado da Justiça, APERJ, 1993. p. 19.

${ }^{6}$ A bibliografia sobre o tema é extensa. Cf. ALMEIDA JÚNIOR, Antonio. Sob as arcadas. Rio de Janeiro: Centro Brasileiro de Pesquisas Educacionais, Instituto Nacional de Estudos Pedagógicos, Ministério da Educação e Cultura, 1965. DULLES, John W. F. A Faculdade de Direito de São Paulo e a resistência anti-Vargas (1938-1945). Rio de Janeiro: Nova Fronteira; São Paulo: Edusp, 1984. SALDANHA, Alberto. A UNE e o mito do poder jovem. Maceió: EDUFAL, 2005. POERNER, Artur José. O poder jovem: história da participação política dos estudantes brasileiros. 2. ed. Rio de Janeiro: Civilização Brasileira, 1979.

7 Os estudantes integralistas vão processar o superintendente da Ordem Política e Social. Diário de São Paulo, São Paulo, 29.8.1935, Doc. 145, Fl. 23. Prisão de estudantes integralistas. Diário da Noite, São Paulo, 29.8.1935, Doc. 127, Fl. 5. Prontuário 1583, Ação Integralista, v. 2. DEOPS/SP. AESP.

8 Prontuário 33237, Bento Luiz de Almeida Prado. DEOPS/SP. AESP. Prontuário 83135, Carlos Jacyntho de Barros. DEOPS/SP. AESP. Prontuário 83132, Joaquim Magalhães Costa. DEOPS/SP. AESP.

9 Prontuário 41385, Lafayette Soares de Paula. DEOPS/SP. AESP. 
${ }^{10}$ Termo de Declarações de Roland Corbisier para Delegado de Ordem Política. Gabinete de Investigações, São Paulo, 26 de março de 1938, F1. 82. Prontuário 82685, Roland Corbisier. DEOPS/SP. AESP.

${ }^{11}$ TRINDADE, Hélgio. Integralismo (O fascismo brasileiro na década de 30). São Paulo: Difusão Européia do Livro, 1974. p. 152.

${ }^{12}$ Ibidem, p. 124-125.

${ }^{13}$ TRINDADE, Hélgio. Integralismo. In: ABREU, Alzira Alves de et al. (coords.). Dicionário Histórico Biográfico Brasileiro. Rio de Janeiro: FGV/CPDOC, 2001. p. 2810.

${ }^{14}$ Ibidem.

${ }^{15}$ RÜSEN, Jörn. Razão histórica: teoria da história: fundamentos da ciência histórica. Brasília: Editora da Universidade de Brasília, 2001.

${ }^{16} \mathrm{O}$ Integralismo atribuiu à imprensa um papel central na doutrinação. A estrutura era respeitável: jornais diários nos principais estados do Brasil (Rio de Janeiro, São Paulo, Minas Gerais, Paraná, Rio Grande do Sul, Maranhão, Ceará, Bahia, Pernambuco e Alagoas), além de semanários e quinzenários espalhados por todas as províncias; revistas (Anauê, Brasil Feminino, Sigma e Panorama); um número aproximado de 3.000 boletins e similares com informações sobre os vários núcleos. CAVALARI, R. M. F.. Integralismo: ideologia e organização de um partido de massas no Brasil (1932-1937). Bauru: Edusc, 1999. p. 87.

${ }^{17}$ VIANA, Giovanny Noceti. Orientar e disciplinar a liberdade: um estudo sobre a educação nas milícias juvenis integralistas - 1934/1937. Dissertação de mestrado, História, Departamento de História, Centro de Filosofia e Ciências Humanas, Universidade Federal de Santa Catarina, 2008, p. 129-130.

${ }^{18}$ Panfleto Mocidade de Cachoeira! Pais de Família. São Paulo, c. 1935. Doc. 193, Fl. 71. Pront. 1583, Ação Integralista, v. 2. DEOPS/SP. AESP.

${ }^{19}$ A ideologia integralista foi objeto de análises complexas. Cf. CHASIN, Jean. O Integralismo de Plínio Salgado: forma de regressividade no capitalismo hipertardio. São Paulo: Ciências Humanas, 1978. CHAUÍ, Marilena. Apontamentos para uma crítica da Ação Integralista Brasileira. In: CHAUÍ, Marilena; FRANCO, Maria S. Carvalho. Ideologia e mobilização popular. Rio de Janeiro: CEDEC/Paz e Terra, 1978. VASCONCELLOS, Gilberto. A ideologia curupira: análise do discurso integralista. São Paulo: Brasiliense, 1977.

${ }^{20}$ Sobre a importância da família no discurso e na prática integralista consultar: GERALDO, Endrica. Entre a raça e a nação: a família como alvo nos projetos eugenista e integralista de nação brasileira nas décadas de 1920 e 1930. Dissertação de mestrado, História, Departamento de História, Instituto de Filosofia e Ciências Humanas, Universidade Estadual de Campinas, 2001.

${ }^{21}$ ARAÚJO, Ricardo Benzaquen de. Totalitarismo e revolução: o integralismo de Plínio Salgado. Rio de Janeiro: Zahar, 1988.

22 SALGADO, Plínio. Literatura e Política (1927). In: . Obras Completas. São Paulo: Américas, 1956, v. 19, p. 85.

${ }^{23}$ SALGADO, Plínio apud MEDEIROS, Jarbas. Introdução ao estudo do pensamento político autoritário brasileiro - 1914-18/1939-45 - Plínio Salgado. Revista de Ciência Política, Rio de Janeiro, v. 18, n. 3, 1975, p. 59. 
${ }^{24}$ Ibidem, p. 61.

${ }^{25}$ SALGADO, Plínio. Literatura e Política. In: 1956 , v. 19 , p. 31. , Obras Completas. São Paulo: Américas,

${ }^{26}$ MAIO, Marcos Chor; CYTRYNOWICZ, Roney. Op. cit., p. 50.

${ }^{27}$ Para estudo detalhado sobre o Integralismo e a imprensa: CAVALARI, Rosa Maria Feiteiro. Op. cit.

${ }^{28}$ APRESENTAÇÃO. Panorama, São Paulo, ano I, n. 1, jan. 1936, p. 1.

${ }^{29}$ Ibidem, p. 2.

${ }^{30}$ LIMA, Maria Letícia Ferreira. O nacionalismo na escola primária. Panorama, São Paulo, ano I, n. 2, fev. 1936, p. 39-43.

${ }^{31}$ Ibidem, p. 39.

${ }^{32}$ Ibidem, p. 41.

${ }^{33}$ ALVES, Isaias. A Disciplina na Escola Alemã. Panorama, São Paulo, ano I, n. 2, fev. 1936, p. 47-48.

${ }^{34}$ TRINDADE, Hélgio. Integralismo. In: ABREU, Alzira Alves de et al. (coords.). Op. cit., p. 2810.

${ }^{35}$ CÂMARA, Hélder. Pedagogia Integralista. Panorama, São Paulo, ano I, n. 3, mar. 1936, p. 26-30. Trata-se da transcrição de discurso proferido em cerimônia de colação de grau na qual foi paraninfo. Há vasta historiografia sobre as disputas políticas e ideológicas envolvendo a educação. Cf.: CURY, Carlos Roberto Jamil. Ideologia e educação brasileira. São Paulo: Cortez \& Moraes, 1978. CUNHA, Célio da. Educação e autoritarismo no Estado Novo. São Paulo: Cortez/ Autores Associados, 1981. SCHWARTZMAN, Simon; BOMENY, Helena Maria Bousquet; COSTA, Vanda Maria Ribeiro. Op. cit.

${ }^{36}$ Ibidem, p. 26.

${ }^{37}$ Ibidem, p. 27.

${ }^{38}$ Ibidem, p. 28.

${ }^{39}$ Ibidem.

${ }^{40}$ TRINDADE, Hélgio. Op. cit., p. 179-181. VIANA, Giovanny Noceti. Op. cit., p. 82-93. O historiador Giovanny Noceti Viana constatou certo impasse na terminologia adotada para designar as divisões no integralismo. As divisões seriam chamadas de Departamentos até 1936, por ocasião do Congresso de Petrópolis, quando teriam sua nomenclatura alterada para Secretarias. Em sua pesquisa ele adota o termo Secretaria, seguindo o que registra o jornal Monitor Integralista, órgão oficial do partido e uma das fontes consultadas em sua pesquisa. $\mathrm{O}$ impasse pode ser explicado pelo pouco tempo do integralismo, insuficiente para a consolidação de uma terminologia oficial. Fundado em 1932, já em 1938 foi fechado pelo governo Vargas.

${ }^{41}$ Regulamento da S.N.A.F.P., artigo 1 apud TRINDADE, Hélgio. Op. cit., p. 195.

${ }^{42}$ TRINDADE, Hélgio. Op. cit., p. 187; 195.

${ }^{43}$ Protocolos e Rituais, Capítulo X, artigo 55 apud CAVALARI, R. M. F. Op. cit., p. 173.

${ }^{44}$ Ibidem, p. 176. 
${ }^{45}$ TRINDADE, Hélgio. Op. cit., p. 205-206.

${ }^{46}$ Protocolos e Rituais, Capítulo VI, artigo 51 apud CAVALARI, R. M. F. Op. cit., p. 198.

${ }^{47}$ Protocolos e Rituais, Capítulo X, artigo 148 apud CAVALARI, R. M. F. Op. cit., p. 170.

${ }^{48}$ Ibidem.

${ }^{49}$ Para uma análise da disputa entre as forças políticas pela juventude: SANTANA, Márcio Santos de. Projetos para as novas gerações: juventudes e relações de força na política brasileira (1924-1945). Tese de doutorado, História, Departamento de História, Faculdade de Filosofia, Letras e Ciências Humanas, Universidade de São Paulo, 2009.

${ }^{50}$ FURET, François. O passado de uma ilusão: ensaio sobre a ideia comunista no século XX. São Paulo: Siciliano, 1995. p. 12.

${ }^{51}$ CAMBI, Franco. História da Pedagogia. São Paulo: UNESP, 1999. p. 392.

${ }^{52}$ RÜSEN, Jörn. Op. cit., p. 59.

\section{Artigo recebido em novembro de 2011. Aceito em dezembro de 2011.}

